\title{
Management of Foreign Market Entry: A Study of Czech Companies
}

\author{
Šárka Zapletalová \\ Moravian University College, Olomouc, Czech Republic
}

\begin{abstract}
Internationalization of company activities is the necessity of the development for majority of entrepreneurial subjects in the Czech Republic. Internationalization of entrepreneurial activities becomes a tool of business competitiveness. Selecting the right foreign entry mode is an important decision, which demands a lot of resources and thorough planning. The factors influencing company's choice of entry mode are divided into two main groups subsuming-external and internal factors. External factors consist of determinants regarding the company's environment while the internal ones are determined by the company's specific factors. The opening of new markets such as in the Czech Republic has created the potential for small and medium-size enterprise (SME) expansion and investment. The objective of this paper is to present an application of the entry modes of the selected Czech entrepreneurial subjects. The companies included in the study are those that have undertaken internationalization activities and are incorporated in the Czech Republic. There were a total of 297 enterprises that participated in the research. The research method was an oral questioning and the main instrument was a questionnaire. A relatively low degree of Czech companies that have undergone internationalization has resulted in the dominance of the least advanced forms of internationalization expansion, mainly exports with a small share of more advanced forms of foreign direct investments and a very low level of forms of international cooperation. Czech companies are in decision about the choosing the foreign entry mode influenced by the many factors. The greatest influence on the choice of foreign entry mode has entry mode variables. Entry mode variables constitute variables assessment characteristics of particular entry mode.
\end{abstract}

Keywords: foreign market entry modes, internationalization process, foreign markets

\section{Introduction}

Small and medium enterprises (SME) currently play an important role in international business. The internationalization process of SMEs and company's decision to sell its products in international markets has been the subject of intense academic research in the past 40 years. Several theories and conceptual frameworks have been developed outlining a company's decision to initiate the internationalization process. The foreign market entry selection is highly significant for the company's future performance. One of the crucial strategic decisions an international company has to make is selecting a mode for entering a new foreign market. There are several market entry modes a company can choose from. Each entry mode contains commitments and risks

Šárka Zapletalová, assistant professor, Department of Management and Marketing, Moravian University College, Olomouc, Czech Republic.

Correspondence concerning this article should be addressed to Šárka Zapletalová, Moravian University College Olomouc, tř. Kosmonautů 1288/1, 77900 Olomouc, Czech Republic. E-mail: szapletalova@hotmail.com. 
as well as control and potential profits. Of empirical interest in this paper are the three distinct groups of the foreign market entry modes: export entry modes, contractual entry modes, and investment entry modes.

One of the main reasons of the interest of Czech companies to expand to foreign markets nowadays is a limited market size of the Czech Republic and, consequently, the increasing competition in the domestic market. The growing interest in doing business in foreign markets gives rise to interests in internationalization in a broader context. However, the research on international entrepreneurship and internationalization processes in Czech professional and business literature is relatively scarce; there are only few studies exploring and monitoring internationalization processes of Czech companies. Due to the absence of substantial research, the author of the present study carried out a research survey among Czech companies to identify specifics of the internationalization process of selected Czech companies and tried to define and explore internationalization models of Czech companies. The findings presented in the study are the first of their kind in the Czech Republic. The main research question of the research is to find out what the specifics of the internationalization process of entrepreneurial activities of Czech companies are, whether it is possible to determine any specific model of internationalization of Czech companies.

The objective of this paper is to present an application of the entry modes of the selected Czech entrepreneurial subjects. The paper is organized into three parts. The first part presents main entry modes used to internationalize entrepreneurial activities. The second part of the paper will present the results based on the surveyed Czech entrepreneurial subjects. The last section provides conclusions and discusses important implications.

\section{Theoretical Framework}

The companies that decide to enter international entrepreneurship must be aware both of entrepreneurship opportunities and risks, which are inseparably connected with entrepreneurship. Avoiding business opportunity risks does not lead to economic growth but results in missing business opportunities. The companies that decide to enter international market undergo particular stages of internalization. The progress and speed of business activity internalization depend on the interest and role that is assumed to the international entrepreneurship within entrepreneurship strategy of the company.

The ways of entering international market are influenced by company strategic analysis and target international business analysis. The choice of a particular way of entering international market has been influenced by several factors such as investment demands of a company's entering international market, company's disposable sources, target market potential, the level of business activities control, potential event risk when entering the market, and company competitiveness on the market.

Once a company decides to enter an international market, it must select an appropriate entry mode (Erramilli \& Rao, 1993; Burgel \& Murray, 2000). A foreign market entry mode is defined as "an institutional arrangement that makes possible the entry of a company's products, technology, human skills, management, or other resources into a foreign country" (Root, 1994). According to Bradley (2002), the concept of market entry refers to the difficulty or ease a company face, when entering international markets, "Entry is one of the supreme tests of competitive ability. No longer is the company providing itself on familiar ground, instead it has to expose its competences in a new area" (Bradley, 2002, p. 244).

There are several theoretical streams dealing with this choice, such as the economic factor analysis, transaction cost analysis, resource-based theory, the OLI model, and behavioral theory. These theoretical 
backgrounds provide a description of large mode selection. The research on an international entry mode choice has tended to concentrate on large companies. The research findings suggest that due to the fact that SMEs differ from their larger competitors, their mode choice may also differ. Among characteristics of SMEs affecting the mode choice were included these characteristics: managerial and financial resources (Zacharakis, 1997), the ability to service small niche markets (Yap \& Souder, 1994), and less innovative of the SME technology (Tether, Smith, \& Thwaites, 1997). Hollenstein (2005) has explained that the internationalization process of SMEs involves limitations of resources in form of finance, information, and management capacity to a much higher extent for multinational cooperation's. On the other hand, Bradley, Meyer, and Gao (2006) have argued that many SMEs are forced to internationalize, particularly high technology companies, due to the focus on niche markets, shorter product life cycles and frequently, the small size of their domestic markets relative to the potential that exists abroad. Because of the specifics of SMEs, it is unclear whether large company mode choice theories can be applied.

Some researches, like Burgel and Murray (2000) and others (Jones, 1999; Zacharakis, 1997), have suggested that SME entry mode selection has so far received little attention. Choosing a suitable international entry mode can have significant impact on SMEs. Companies entering foreign markets choose different entry modes ranging (Rasheed, 2005). The foreign market entry modes can be divided into three groups: export entry modes, contractual entry modes, and investment entry modes. Export entry modes include direct and indirect exporting. Contractual entry modes include licensing, franchising, contract manufacturing, service contract, construction/turkey contracts, management contracts, and co-production agreements. The third group, investment entry modes, includes joint ventures, foreign direct investment (greenfield investments, acquisitions and mergers), and strategic alliances.

A company seeking to enter a foreign market must make an important strategic decision on which entry mode was used for a particular market. Because all of these modes involve resource commitments, companies' initial choices of a particular mode are difficult to change without a considerable loss of time and money. Entry mode selection is therefore very important, if not a critical and strategic decision.

Managers need to consider what the best way for the company to enter a specific market is and take into consideration the risk and environmental factors that are associated with the different entry strategies (Deresky, 2000). Previous studies in the area of international trade have identified a number of factors that influence the choice of an entry mode for a selected target market. The normative decision theory suggests that the choice of a foreign market entry mode should be based on trade-offs between risks and returns. A company is expected to choose the entry mode that offers the highest risk-adjusted return on investment. The behavioral evidence theory indicates that a company's choices may also be determined by resource availability and the need for control. Resource availability refers to the financial and managerial capacity of a company for serving a particular foreign market. Control refers to a company's need to influence systems, methods, and decisions in that foreign market. Entry mode choices are often a compromise among these four attributes.

The factors influencing company's choice of entry mode are according to Johanson and Vahlne (1977) divided into two main groups, external factors and internal factors. Koch (2001) introduced a holistic model of the market and market entry mode selection process. All factors proposed to influence the market/market entry mode selection process fall into three broad categories: external, internal, and the mixed category. According to Koch (2001), the external category includes industry feasibility, characteristics of the country business environment, market growth rate, image support requirements, global management efficiency requirements, 
popularity of individual market entry modes in the overseas market, market barriers, etc.. The internal category includes calculation methods applied, management locus of control, market share targets, company size and resources, profit targets, management risk attitudes, experience in using individual market entry modes, etc.. The third mixed category includes sufficiency and reliability of information inputs, competencies, capabilities, and skills required and available for each market entry modes. Some of the proposed categories of factors may influence each other, adding to the complexity of the decision process.

In order to fulfill the aim of this paper, the following hypotheses were developed.

Hypothesis 1 : The entry mode is influenced by incentive to entry to foreign markets.

Hypothesis 2: The entry mode is influenced by using of business partners.

Hypothesis 3: The entry mode is influenced by the level of knowledge of the target foreign market.

Hypothesis 4: The entry mode is influenced by business activities.

Hypothesis 5: The entry mode is influenced by the choice of geographical sub-region at the first international entry.

Hypothesis 6: The entry mode is influenced by the choice of cultural cluster at the moment of the first international entry.

Hypothesis 7: The entry mode is influenced by the number years of the international management experience at the first international entry.

Hypothesis 8: The entry mode is influenced by the age of the company at the first international entry.

Hypothesis 9: The entry mode is influenced by the number of geographical sub-regions at the first international entry.

Hypothesis 10: The entry mode is influenced by the number of target foreign markets at the first international entry.

Hypothesis 11: The entry mode is influenced by the number of cultural clusters at the first international entry.

Hypothesis 12 : The entry mode is influenced by the size of the company.

\section{Materials and Methods}

This paper presents the results of research that focused on application of the entry modes of the selected Czech entrepreneurial subjects.

The companies included in the study are those that have undertaken internationalization activities and are incorporated in the Czech Republic. The number of companies that participated in the research (total 297) covers a wide range of industries. The internationalization of the entrepreneurial subjects has been researched using the method of questioning, in particular oral questioning and the main instrument was a questionnaire. In order to ensure a representative sample, the questionnaire was submitted to the selected top managers or directors of enterprises. The total of 297 valid questionnaires was collected, which provided the response rate of 74\%. The research was carried out in the Czech Republic from March 2013 to April 2013.

The dependent variable in this study is the choice of entry modes by Czech companies at the first international entry. The independent variables in this study are: incentive to entry foreign markets, the level of knowledge of the target foreign market, cooperation with another company (Czech or foreign partners), the choice of geographical sub-region at the first international entry, the choice of cultural cluster at the first international entry, the branch of business activity, the number years of the international management 
experience at the first international entry, the age of the company at the first international entry, the number of geographical sub-regions at the first international entry, the number of target foreign markets at the first international entry, and the number of the cultural clusters at the first international entry and the company size (size is determined by the number of employees).

\section{Results and Discussion}

The research subsumes a two-stage analytical method. The first stage includes categorical data analysis and ANOVA analysis. The second stage draws on factor analysis. The analysis began by examining the correlation between variables. All variables were screened to reveal their distribution through Pearson correlation coefficients. The focus has been on the validity of the overall framework by examining the impact of the identified relevant entry mode variables operated together on the final entry mode choice.

The hypotheses 1 to 6 were tested through categorical data analysis. Table 1 presents the results of the analysis.

Table 1

Categorical Data Analysis for Hypothesis 1 to 6

\begin{tabular}{lccll}
\hline & \multicolumn{2}{c}{ Pearson Chi-square } & Cramer's $V$ & Asymp. Sig. \\
\cline { 2 - 5 } & \multicolumn{1}{c}{ Value } & df & Value & \\
\hline Hypothesis 1 & 404.817 & 343 & 0.441 & 0.012 \\
Hypothesis 2 & 176.538 & 147 & 0.445 & 0.049 \\
Hypothesis 3 & 106.820 & 98 & 0.424 & 0.255 \\
Hypothesis 4 & 116.985 & 98 & 0.444 & 0.093 \\
Hypothesis 5 & $\mathbf{1 , 3 9 4 . 8 3}$ & $\mathbf{1 , 7 1 5}$ & 0.433 & 0.000 \\
Hypothesis 6 & $\mathbf{1 , 4 4 2 . 1 8 8}$ & $\mathbf{1 , 3 7 2}$ & 0.416 & 0.092 \\
\hline
\end{tabular}

Hypothesis 1 presumed that the entry mode is influenced by incentive to entry to foreign markets. This hypothesis has been confirmed: The strength of this relationship is medium $(V=0.441)$, as shown in Table 1 . Hypothesis 2 presumed that the entry mode is influenced by the using of business partners. This hypothesis has been confirmed: The strength of this relationship is medium $(V=0.445)$. Hypothesis 3 presumed that the entry mode is influenced by the level of knowledge of the target foreign market. This hypothesis was not confirmed. In Hypothesis 4, it was assumed that the entry mode is influenced by the business activity: This hypothesis is not supported. Hypothesis 5 presumed that the entry mode is influenced by the choice of geographical sub-region at the first international entry. This hypothesis has been confirmed: The strength of this relationship is medium $(V=0.433)$. Hypothesis 6 presumed that the entry mode is influenced by the choice of cultural cluster at the first international entry: This hypothesis is not supported.

The hypotheses 7 to 12 were tested through ANOVA Analysis. Table 2 presents the results of the analysis.

Hypothesis 7 presumed that the entry mode is influenced by the number years of the international management experience at the first international entry: This hypothesis has been confirmed. Hypothesis 8 presumed that the entry mode is influenced by the age of the company at the first international entry: This hypothesis has been confirmed. Hypothesis 9 presumed that the entry mode is influenced by the number of geographical sub-regions at the first international entry: This hypothesis was not confirmed. In Hypothesis 10, it was assumed that the entry mode is influenced by the number of target foreign markets at the first international entry: This hypothesis is not supported. Hypothesis 11 presumed that the entry mode is influenced 
by the number of cultural clusters at the first international entry: This hypothesis was not confirmed. Hypothesis 12 presumed that the entry mode is influenced by the size of the company: This hypothesis is not supported.

Table 2

Anova Analysis for Hypotheses 7 to 12

\begin{tabular}{|c|c|c|c|c|c|c|}
\hline & & Sum of Squares & $\mathrm{df}$ & Mean Square & $F$ & Sig. \\
\hline \multirow{3}{*}{ Hypothesis 7} & between groups & $2,653.305$ & 49 & 54.149 & 5.462 & 0.000 \\
\hline & within groups & $2,448.499$ & 247 & 9.913 & & \\
\hline & total & $5,101.805$ & 296 & & & \\
\hline \multirow{3}{*}{ Hypothesis 8} & between groups & 28,745.974 & 49 & 586.653 & 2.843 & 0.000 \\
\hline & within groups & $50,975.905$ & 247 & 206.380 & & \\
\hline & total & $79,721.879$ & 296 & & & \\
\hline \multirow[b]{2}{*}{ Hypothesis 9} & between groups & 45.152 & 49 & \multirow{3}{*}{$\begin{array}{l}0.921 \\
1.937\end{array}$} & \multirow[b]{2}{*}{0.476} & \multirow[b]{2}{*}{0.999} \\
\hline & within groups & 478.390 & 247 & & & \\
\hline \multirow{3}{*}{ Hypothesis 10} & $\begin{array}{l}\text { total } \\
\text { between grouns }\end{array}$ & $\begin{array}{r}523.542 \\
2,253.641\end{array}$ & $\begin{array}{r}296 \\
49\end{array}$ & & \multirow{3}{*}{0.571} & \multirow{3}{*}{0.990} \\
\hline & within groups & $19,902.163$ & 247 & \multirow{2}{*}{$\begin{array}{l}45.993 \\
80.576\end{array}$} & & \\
\hline & total & $22,155.805$ & 296 & & & \\
\hline \multirow{3}{*}{ Hypothesis 11} & between groups & 61.964 & 49 & & \multirow{3}{*}{0.961} & \multirow{3}{*}{0.551} \\
\hline & within groups & 324.871 & 247 & 1.265 & & \\
\hline & total & 386.835 & 296 & & & \\
\hline \multirow{3}{*}{ Hypothesis 12} & between groups & $10,497,072$ & 49 & & \multirow{3}{*}{1.214} & \multirow{3}{*}{0.173} \\
\hline & within groups & $43,590,554$ & 247 & $\begin{array}{l}214,225.954 \\
176479977\end{array}$ & & \\
\hline & total & $54,087,626$ & 296 & & & \\
\hline
\end{tabular}

Furthermore, the factor analysis has been carried out due to the specification of factors affecting the choice of entry mode: It draws on 25 specified criteria as shown in Table 3. The criteria are based on information offered due to personal communication with selected experts from business and universities and on the basis of previous researches. Respondents expressed their opinion for the importance of each criterion by using the five-point Likert Scale ( $5=$ strongly agree to $1=$ strongly degree). The reliability of measurements was acceptable (Table 3). The total reliability reached the value of $\alpha=0.865$, standardized item $\alpha=0.865$.

Varimax rotation was performed. Seven factors with eigen-values greater than 1 were extracted. The factors loading greater than 0.5 are shown in bold. The results of the factor analysis are shown in Table 4 .

Factor analysis extracted seven factors with eigen-value greater than 1: Along with the observed loadings, this indicates the convergent and discriminant validity of these constructs. The factor loadings structure was employed to determine the factor scores of each company on the seven constructs. All the scale items loaded highly on factors they represented and weakly on other factors. The seven factors accounted for $57.7 \%$ of the total variation in the sample. Those seven factors determine the choice of entry mode. Factor 1 "macrolevel factor" is formed by the factors of macro-level (infrastructure, political stability, social and cultural differences, right and legislation, foreign trade policy). Factor 2 "target market factor" characterizes the target market in terms of entry preparation (preparation time, chosen target market, knowledge and information about target market). Factor 3 "factor of method characteristics" is connected with basic characteristics of specify method (flexibility of method, risk of method, degree of control). Factor 4 "company factor" defines fundamental characteristics (or identification) of the company such as the company size and product type for foreign markets. Factor 5 "factor of market attractiveness" describes market attractiveness both in the terms of the economical and localization. Factor 6 "cost factor" is formed by production costs and sales costs. Finally, factor 6 "resources factor" defines necessary resources for the method. 
Table 3

Evaluation of Choice Criteria

\begin{tabular}{|c|c|c|}
\hline Criterion $(\alpha)$ & mean & rank \\
\hline Return on investments $(0.865)$ & 4.68 & 1 \\
\hline Necessary resources for the method $(0.864)$ & 4.43 & 2 \\
\hline Knowledge and information about target market (0.859) & 4.31 & 3 \\
\hline Intensity of competition ( 0.862$)$ & 4.22 & 4 \\
\hline Risks of the method (0.862) & 4.21 & 5 \\
\hline Sales costs in the target market $(0.858)$ & 4.10 & 6 \\
\hline Long-term goals of the company $(0.862)$ & 4.09 & 7 \\
\hline Degree of the control method $(0.861)$ & 4.03 & 8 \\
\hline Market barriers in the target market $(0.856)$ & 4.03 & 9 \\
\hline Chosen target market $(0.859)$ & 4.01 & 10 \\
\hline Market size and rate of growth market $(0.860)$ & 3.92 & 11 \\
\hline Type of product for foreign markets $(0.863)$ & 3.89 & 12 \\
\hline Flexibility of the method (0.862) & 3.82 & 13 \\
\hline Right and legislation of the target market $(0.858)$ & 3.71 & 14 \\
\hline Tax environment in the target market $(0.858)$ & 3.70 & 15 \\
\hline International management experience $(0.859)$ & 3.67 & 16 \\
\hline Preparation time for entry into the target market $(0.859)$ & 3.66 & 17 \\
\hline Production costs in the target market $(0.864)$ & 3.64 & 18 \\
\hline Political stability of the country $(0.858)$ & 3.49 & 19 \\
\hline Infrastructure in the target market $(0.859)$ & 3.46 & 20 \\
\hline Geographical distance of the target market $(0.865)$ & 3.44 & 21 \\
\hline Foreign trade policy of the home market $(0.855)$ & 3.42 & 22 \\
\hline Foreign trade policy of the target market $(0.853)$ & 3.41 & 23 \\
\hline Size of the company $(0.863)$ & 3.15 & 24 \\
\hline Social and cultural differences between home market and target market $(0.856)$ & 2.86 & 25 \\
\hline
\end{tabular}

Table 4

Factor Analysis

\begin{tabular}{|c|c|c|c|c|c|c|c|}
\hline \multirow{2}{*}{ Items } & \multicolumn{7}{|c|}{ Factors } \\
\hline & 1 & 2 & 3 & 4 & 5 & 6 & 7 \\
\hline Necessary resources for the method & -0.031 & -0.055 & 0.455 & -0.040 & -0.025 & 0.153 & 0.622 \\
\hline Flexibility of the method & 0.100 & 0.051 & 0.724 & 0.305 & -0.020 & -0.053 & 0.022 \\
\hline Risks of the method & 0.079 & 0.150 & 0.726 & -0.117 & 0.166 & 0.074 & 0.139 \\
\hline Degree of the control method & 0.185 & 0.150 & 0.628 & 0.167 & 0.022 & 0.042 & 0.008 \\
\hline Return on investments & 0.001 & 0.266 & 0.333 & -0.299 & 0.202 & 0.133 & 0.025 \\
\hline Type of product for foreign markets & 0.139 & 0.249 & 0.064 & 0.639 & 0.041 & 0.107 & -0.151 \\
\hline Size of the company & 0.072 & 0.062 & 0.107 & 0.726 & 0.141 & 0.053 & 0.102 \\
\hline International management experience & 0.079 & 0.384 & 0.226 & 0.459 & -0.018 & -0.034 & 0.381 \\
\hline Long-term goals of the company & 0.279 & 0.393 & 0.212 & 0.273 & -0.059 & 0.078 & -0.004 \\
\hline Preparation time for entry into the target market & 0.019 & 0.511 & -0.028 & 0.239 & 0.074 & 0.075 & 0.396 \\
\hline Chosen target market & 0.190 & 0.709 & 0.097 & 0.180 & 0.063 & 0.053 & -0.095 \\
\hline Knowledge and information about target market & 0.226 & 0.744 & 0.172 & -0.038 & 0.017 & 0.035 & 0.126 \\
\hline Infrastructure in the target market & 0.559 & 0.106 & 0.163 & 0.090 & 0.075 & 0.204 & -0.065 \\
\hline Production costs in the target market & 0.155 & -0.051 & 0.080 & 0.154 & -0.017 & 0.850 & 0.155 \\
\hline Sales costs in the target market & 0.223 & 0.289 & 0.039 & -0.020 & 0.262 & 0.716 & -0.013 \\
\hline Market barriers in the target market & 0.462 & 0.269 & 0.241 & -0.121 & 0.398 & 0.202 & -0.081 \\
\hline
\end{tabular}


Table 4 to be continued

\begin{tabular}{|c|c|c|c|c|c|c|c|}
\hline \multirow{2}{*}{ Items } & \multicolumn{7}{|c|}{ Factors } \\
\hline & 1 & 2 & 3 & 4 & 5 & 6 & 7 \\
\hline Intensity of competition & 0.182 & 0.053 & 0.035 & -0.075 & 0.740 & 0.172 & -0.025 \\
\hline Market size and rate of growth market & 0.120 & 0.376 & 0.195 & 0.139 & 0.518 & 0.124 & -0.085 \\
\hline Political stability of the country & 0.666 & 0.177 & -0.027 & 0.019 & 0.042 & 0.102 & 0.060 \\
\hline Tax environment in the target market & 0.483 & 0.166 & -0.032 & -0.064 & 0.019 & 0.351 & 0.479 \\
\hline Social and cultural differences between home market and target market & 0.613 & 0.013 & 0.042 & 0.152 & 0.230 & 0.074 & 0.330 \\
\hline Geographical distance of the target market & 0.129 & -0.078 & 0.034 & 0.282 & 0.714 & -0.109 & 0.208 \\
\hline Right and legislation of the target market & 0.577 & 0.099 & -0.066 & -0.032 & 0.242 & -0.083 & 0.404 \\
\hline Foreign trade policy of the target market & 0.825 & 0.104 & 0.167 & 0.100 & 0.081 & 0.011 & 0.064 \\
\hline Foreign trade policy of the home market & 0.780 & 0.127 & 0.137 & 0.122 & 0.088 & 0.071 & -0.098 \\
\hline Eigen-value & 6.140 & 1.968 & 1.482 & 1.318 & 1.244 & 1.205 & 1.059 \\
\hline Percentage of variance explained & 24.562 & 7.872 & 5.926 & 5.273 & 4.977 & 4.821 & 4.237 \\
\hline Cumulative percentage of variance explained & 24.562 & 32.434 & 38.360 & 43.633 & 48.609 & 53.430 & 57.668 \\
\hline
\end{tabular}

Notes. Extraction method: principal component analysis; rotation method: varimax with Kaiser Normalization; Rotation converged in 14 iterations.

It has been found out that Czech companies used for their first entry to the foreign market primarily export entry modes (Figure 1).

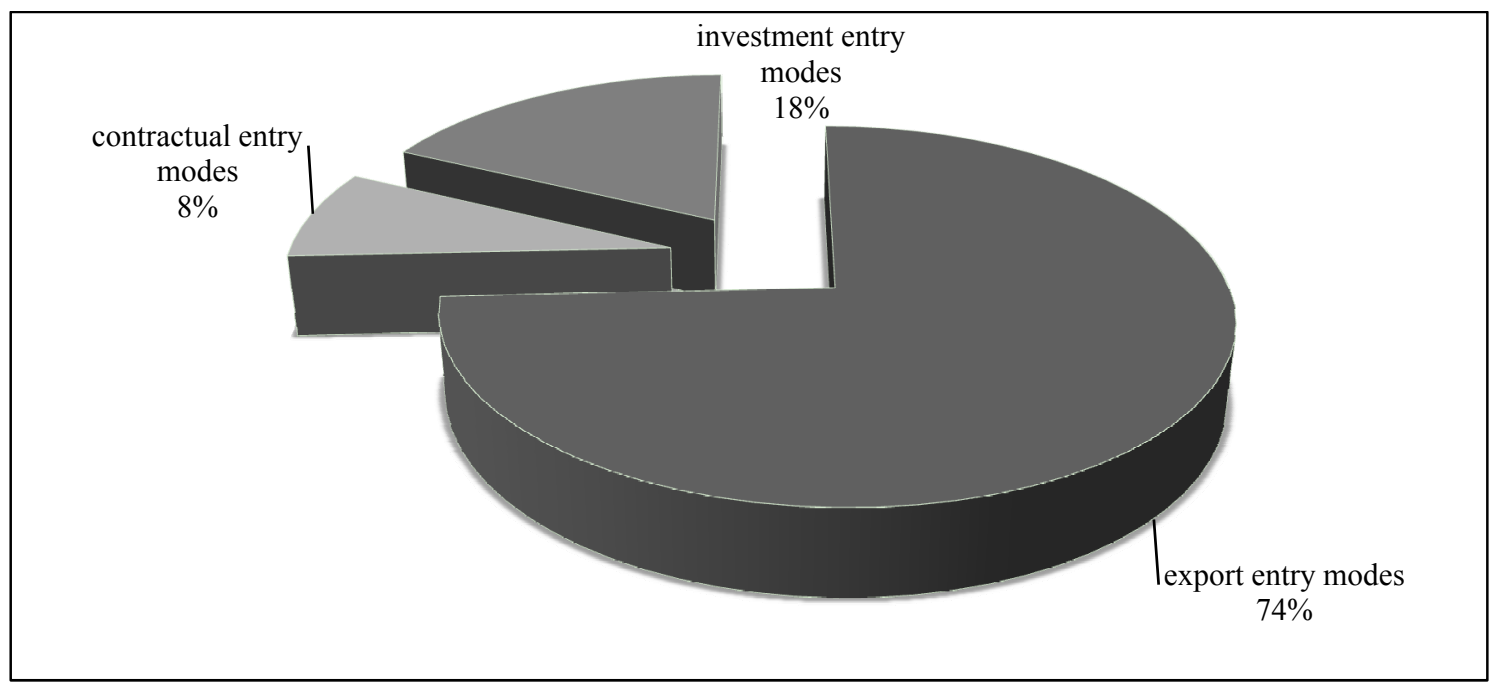

Figure 1. Foreign entry modes of Czech companies.

Ever the most widely used mode has been occasionally direct exporting (51\% respondent). The applied foreign entry modes (when it firsts enters into foreign market) by Czech companies were influenced by incentive to entry, by using of business partner, by the choice of geographical sub-region at the first international entry, by the number years of the international management experience at the first international entry, and by the age of the company at the first international entry.

When deciding which foreign entry mode to choose, most Czech companies are influenced by various factors. With the help of factor analysis, seven factors have been identified. These seven factors can be classified into four main groups: macro-environment variables, entry mode variables, company variables, and market variables. 
As shown in Figure 2, the greatest influence on the choice of foreign entry mode has entry mode variables. Entry mode variables constitute variables assessment characteristics of a particular entry mode. These characteristics include: flexibility of the method, risk of the method, degree of the method control, etc..

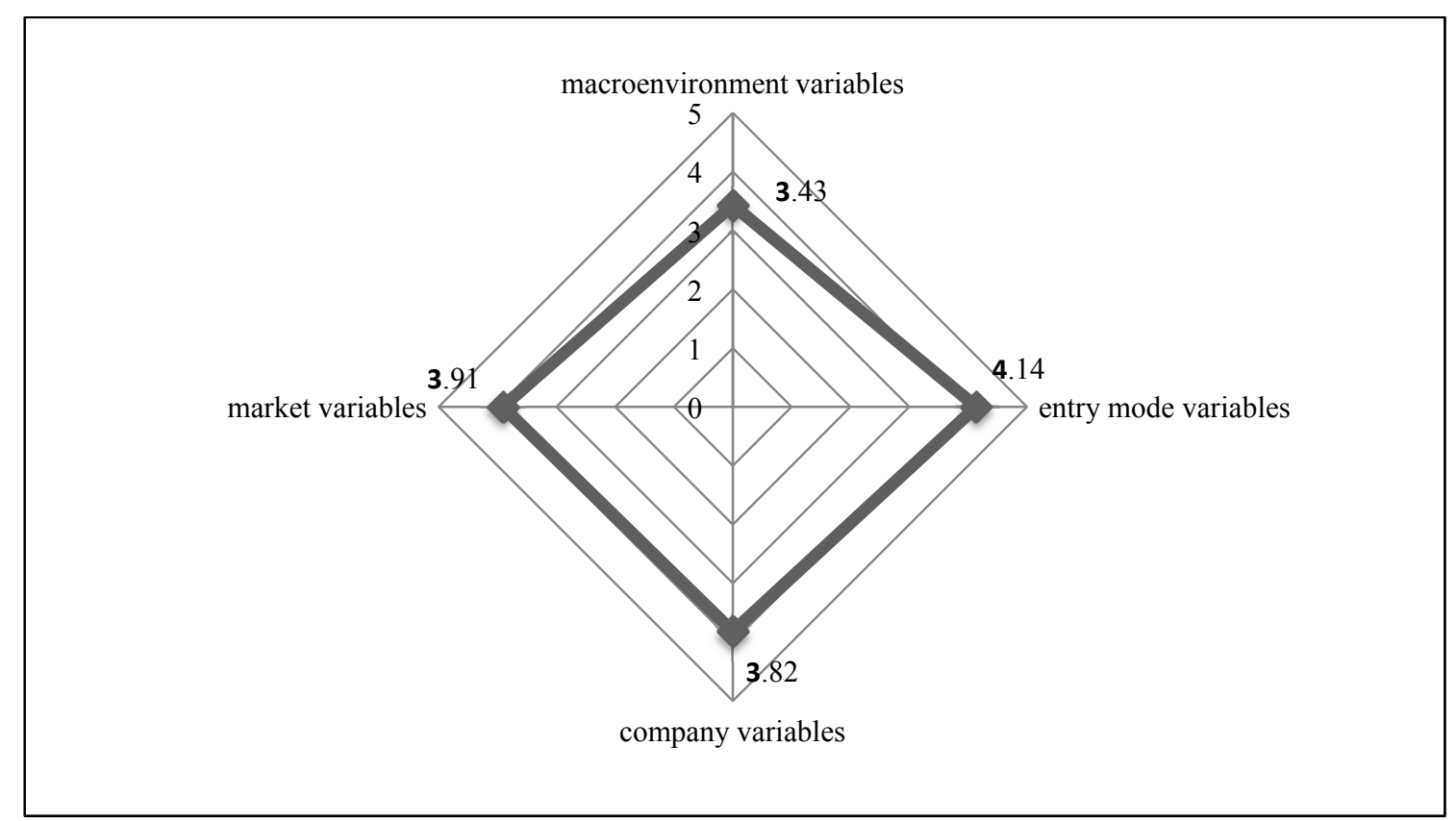

Figure 2. Variables influencing the choice of foreign entry modes.

The second most influential factor group is market variables. Market variables constitute those characteristics of a target market which are significant in terms of entry into foreign markets. These characteristics include: market barriers, intensity of competition, market growth, etc..

Company variables are the third most important group of decisive factors when choosing the foreign entry mode. The group includes factors of internal company environment as company size, product type for foreign markets, international management experience, etc.. Factors of internal company environment determine the possibilities of the company particularly in terms of company resources.

The least influential group of factors according to the investigation of selected Czech companies is macro-environment variables. Macro-environment variables describe macro-environment characteristics both of the domestic and of the foreign country. These characteristics include: political stability, tax conditions, social and cultural differences, right and legislation, etc..

\section{Conclusions}

The major objective of the paper was to present an application of the foreign entry modes of the selected Czech entrepreneurial subjects. The study provided support for hypothesized relationships suggesting the importance of including interaction effects in the entry choice. This study shows that Czech companies have a higher preference for export entry modes. In general, companies do not prefer the investment entry modes and contractual entry modes when risks are higher.

The above findings clearly show that foreign entry mode selection is influenced by factors of entry mode. It was found out that the most influential factor in choosing the foreign entry mode is return on investments. 
The Czech Republic is a country with a high share of exported and imported goods in its GDP which is typical of small countries, of which the country is an example. The Czech entrepreneurial subjects have been increasingly taking part in international market since the beginning of the 21 st century and this trend seems to be growing. Most companies are aware of the necessity of the development of business and entrepreneurship activities international-wide. The necessity of active participation of Czech entrepreneurial subjects at international market is conditioned primarily by the character of Czech economics and its foreign political orientation.

The Czech Republic government has based its actions on these fundamental economic facts and it is fully aware of the exceptional significance of external economic relations and in particular exports for the development of Czech national economy. The Czech government is aware of the fact that despite the comparability of the level of openness of the Czech economy with those of the medium-sized EU countries, the per capita exports for the Czech Republic do not compare favorably. The Czech government is paying significant attention to the fact that the export share of SMEs exceeds an average of $50 \%$ in the EU countries, but only $37 \%$ in the Czech Republic.

\section{References}

Bradley, F. (2002). International marketing strategy (4th ed.). Essex: Pearson Education Limited.

Bradley, F., Meyer, R., \& Gao, Y. (2006). Use of supplier-customer relationships by SMEs to enter foreign markets. Industrial Marketing Management, 35, 652-665.

Burgel, O., \& Murray, G. (2000). The international market entry choices of start-up companies in high-technology industries. Journal of International Marketing, 8(2), 33-62.

Deresky, H. (2000). International management (3rd ed.). Upper Saddle River: Prentice Hall.

Erramilli, M. K., \& Rao, C. P. (1993). Service firms' international entry-mode choice: A modified transaction-cost analysis approach. Journal of Marketing, 57(3), 19-38.

Hollenstein, H. (2005). Determinants of international activities: Are SMEs different? Small Business Economics, 24(5), 431-450.

Johanson, J., \& Vahlne, J. E. (1977). The internationalization process of the firm-A model of knowledge development and increasing foreign market commitments. Journal of International Business Studies, 8, 23-32.

Jones, M. (1999). The internationalization of small high-technology firms. Journal of International Marketing, 7, 15-41.

Koch, A. J. (2001). Factors influencing market and entry mode selection: Developing the MEMS model. Marketing Intelligence \& Planning, 19(5), 411-432.

Rasheed, H. S. (2005). Foreign entry mode and performance: The moderating effects of environment. Journal of Small Business Management, 43(1), 41-54.

Root, F. R. (1994). Entry strategies for international markets. San Francisco: Jossey-Bass, Ing..

Tether, B. S., Smith, I. J., \& Thwaites, A. T. (1997). Smaller enterprises and innovation in the UK: The SPRU innovations database revisited. Reserach Policy, 26(1), 19-32.

Yap, C., \& Souder, W. (1994). Factors influencing new product success and failure in small entrepreneurial high-technology electronic firms. Journal of Product Innovation Management, 11, 418-432.

Zacharakis, A. (1997). Entrepreneurial entry into foreign markets: A transaction cost perspective. Entrepreneurship Theory \& Practice, 21(3), 23-39. 